\title{
Cytotoxic Potentials of Betel Quid and its Components
}

\author{
${ }^{1}$ Lichelyn F. Moling, ${ }^{2}$ Denisa L. Domondon, $\mathrm{PhD}$ \\ ${ }^{I}$ Mountain Province State Polytechnic College, Bontoc Campus, Mountain Province, Philippines \\ ${ }^{2}$ Benguet State University, La Trinidad, Benguet
}

\begin{abstract}
In this research, it aims to determine the potential cytotoxic effects of the betel quid, areca nut, betel leaf and slaked lime extracts using Allium cepaassay through evaluating the root length, chromosome aberration and mitotic index. A series of Allium cepabulbs were exposed to varying concentrations together with a known mutagen, colchicine. The treatment groups consist of: $100 \%$ and $50 \%$ of the betel quid and its components. After 48 hours of exposure, the root tips from the different treatments were processed for cytological studies by aceto-orcein squash technique. The cytotoxic effects of betel quid and its components observed in Alliumcepa root tips showed growth retardation in terms of root length in high concentration. There was a decrease in mitotic index percentage with increasing concentrations. The betel quid and components-induced chromosome aberrations were statistically significant $(p<0.05)$. The result from the cytotoxicity study data revealed that the extracts of the betel quid and its components inhibited the growth of the Allium cepa roots and has potent cytotoxic effects.
\end{abstract}

Keywords: mitotic index, cytotoxic, chromosomal aberration, Allium cepa assay

\section{Introduction}

Chewing of betel quid is traditionally practiced in the subcontinent of India and severalareas in Asia, and is still predominant today. In modern times the term "betel quid" for most people is synonymous with "pan," a chewing item used in India and neighboring countries or "momma" in the Cordilleras. The fruit of Areca catechuis the areca nut. Some may refer to it as "betel nut", but this term is incorrect, as it does not come from the betel plant. The use of areca nut is strongly interwoven into local art and craft, folklore, social customs, religious practices and cultural rituals (Gupta, 2002) in Southeast Asia and the Western Pacific.

According to Bautista in 2007 (Philippine Daily Inquirer, 2007), chewing areca nut mixed with lime has been a practice among Cordillera tribes because they believe it could strengthen their teeth and promote oral hygiene but is carcinogenic and it does not make the teeth stronger. Areca nut "fuwa"is consumed either on its own or more commonly in association with other ingredients such as tobacco, lime "apog" and other spices wrapped in a betel leaf locally called as "gawed" and the combination of these areca nut, betel leaf and slaked lime is termed as "momma" in the Philippines and in some countries, it is denoted as betel quid. The components may be wrapped simultaneously in the betel leaf and chewed or may be placed in the mouth separately depending on the person chewing the betel quid. The betel leaf is edible and is added to the quid to enhance its flavor. It contains betel oil, which includes phenolic compounds such as hydroxychevicol, euginol phenol, and chevicol while slaked lime is a white, dry fine powder, free from lumps, possessing an alkaline, slightly bitter taste. The betel leaves are aromatic with varied taste, ranging from sweet to pungent due to the presence of essential oils (Pradhan, 2013). When areca nut, slaked lime and betel leaves are chewed together in the quid, the resultant chew turns bright red. With the rising number of oral cancer in the country, the president of the Philippine Dental Association Dr.Jenee Bautista warned the Cordillerans in 2007 on betel nut chewing as it leads to oral malignancy. Arecoline and guvacoline are found to decrease cell survival and deplete intracellular thiols (Sharan et al., 2012). 
This study is based on the fact that betel quid is often used with insufficient attention given to its varied contents and practices in different parts of the world. The betel quid generally contains betel leaf, areca nut and slaked lime. Areca nut is the basic ingredient of a variety of widely used chewed products that contains arecoline and guvacoline (IARC, 2004). The betel leaf was found to be containing cytotoxic compounds but this result does not necessarily suggest complete toxicity of the plant. (Del Socorro et al., 2104). The slaked lime(calcium hydroxide) combined with areca nut primarily triggers the reactive oxygen species to develop which may possibly cause DNA oxidation leading to the damageofmucosa cells in the mouthof betel quid chewers(Nair et al., 1990). It is conceptualized that betel quid and its components has been linked to the pathobiological effects and development of oral cancer with the presence of the four areca nut alkaloids and four nitrosated derivatives (Sundqvist et al., 1989).

Among the higher plant species, Allium cepa is well known and commonly used in many laboratories because A. cepa is a remarkableexperimental plant with many advantages such as low cost, a large number of roots, short test time, ease of storage and handling, large cells with excellent chromosome conditions, and ease of observing abnormal phenomena of chromosomes, nuclei, and nucleoli affected during mitosis (Liu et al., 1995).This present study aims to determine the cytotoxic effects of the extracts of the betel quid itself, areca nut, betel leaf and slaked lime using Allium cepa Assay to observe possible occurrence of chromosome aberrations in the onion root tips cells.

\section{Method}

\section{Place and Time of the Study}

The study was conducted in April-June, 2016. Growing of Allium cepafor Allium cepa assay was done in the Department of Biology, CAS-BSU, La Trinidad, Benguet.

\section{Design}

The study was conducted to determine the cytotoxic potentials of betel quid and its component. The data that were that were taken from the study were statistically treated using the one-way Analysis of Variance (ANOVA) of the Complete Randomized Design (CRD). Specific significant differences between the means was determined using the Duncan's Multiple Range Test (DMRT). In the DMRT, the means of the control group was compared to the means of the plant and lime extracts.

\section{Materials}

The major components of the betel quid such as the areca nut, betel leaf and slaked lime samples were acquired from the Baguio City Market.

\section{Procedure}

Preparation of Betel Quid Extract

The different components of betel quid were combined and prepared in the laboratory based on the proportions that were usually prepared by the betel quid chewers.

Preparation of Areca Nut Extract

100 grams of Areca nut was crushed using a mortar and pestle until a uniform consistency was gained. The homogenized sample was put into a $250 \mathrm{~mL}$ volumetric flask with the addition of $90 \%$ ethanol to a volume of $250 \mathrm{~mL}$ for two days. This was then filtered using Whatman No.4 filter paper.

Preparation of Betel Leaf Extract

About 60 grams of the betel leaf plant samples were submerged with $250 \mathrm{~mL}$ of $95 \%$ ethanol for three days and then filtered with Whatmann No. 1 filter paper. The filtrate was then subjected to evaporation through a rotavaporizer for eight hours. 
Cytotoxicity Study: The AlliumcepaTest

The procedure followed in this study was a modified version of the Allium Test initially developed by Fiskesjo (1985). The Alliumcepawas used as a test organism for the initial testing of the cytotoxicity activity of the plant and slaked lime samples. A total of $100 \mathrm{~A}$. сера $(10 \mathrm{~A}$. cepa/treatment) with approximately $1.5 \mathrm{~cm}$ in diameter were selected and initially grown in the distilled water for three days so rootlets can emerge. After this period, the $A$. cepa were transferred to the different treatments. The Allium cepatest was carried out with two sample concentrations. One composed of the $100 \%$ as the highest concentration followed by $50 \%$ as the lowest concentration. distilled water was used as a negative control and colchicine as the positive control.

After two days of growth, three of the best growing A. cepabulbs per set-up were taken at 12:00 pm to 2:00 pm for microscopic examination of the root tip. For each treatment, the grown root tips of A. cepawere measured and three slides were prepared using the following procedure: 1-2 root tips at a length of $10 \mathrm{~mm}$ were cut off and placed immediately in a test tube with Formal Acetic Alcohol (FAA) solution for fixation. For microscopic analysis, the rootlets were washed with distilled water for few minutes and submerged in $1 \mathrm{~N} \mathrm{HCl} \mathrm{for} \mathrm{5-6} \mathrm{minutes} \mathrm{and} \mathrm{rinsed}$ again with distilled water. Thus, the root tips were fixed and macerated. The squash technique was followed in the slide preparation (Guerra and Souza, 2002). Approximately 1-2 mm of the terminal root tips were cut and placed on glass slides. Two drops of freshly prepared $2 \%$ aceto-orcein were dropped on the tips and left for 20 minutes. The root tips were covered with the glass slip and pressed flat to squash the cells.

\section{Results}

Cytotoxic Effects of the Betel Quid and its Components in Terms of Root Length

Root length is probably the most frequently measured morphological parameter of roots. The longest root from the whole root bundle was measured by a ruler. Table 1 presents the effects of the Betel quid and its components in terms of root length. The measured average root length is $46 \mathrm{~mm}$ in negative control and $10.33 \mathrm{~mm}$ in positive control. However, the average root length in betel quid, areca nut, betel leaf and slaked lime treatment group were decreased significantly compared to that of the negative control. Average root lengths in treatment groups were decreased depending on the treatment, significantly.

Statistical analysis of the different treatments showed that the betel quid and its components significantly affected the growth of onion roots. The $100 \%$ and 50\% concentrations of the betel quid and its components were not significantly different from each other except for the slaked lime where the length of roots treated with 50\% concentration were significantly longer than the $100 \%$ slaked lime concentration.

Table 1. Mean length ( $\mathrm{mm}$ ) of onion roots as affected by betel quid and its components

\begin{tabular}{|c|c|c|c|}
\hline COMPONENTS & MEAN (mm) & F-VALUE & SIG. \\
\hline Negative Control (Distilled water) & $46.00^{\mathrm{a}}$ & $57.450 * *$ & 0.000 \\
\hline Positive Control (Colchicine) & $10.33^{\mathrm{e}}$ & & \\
\hline Betel Quid (100\%) & $11.67^{\mathrm{de}}$ & & \\
\hline Betel Quid (50\%) & $14.67^{\mathrm{cd}}$ & & \\
\hline Areca Nut $(100 \%)$ & $15.00^{\mathrm{cd}}$ & & \\
\hline Areca Nut $(50 \%)$ & $17.67^{\mathrm{c}}$ & & \\
\hline Betel Leaf $(100 \%)$ & $23.00^{\mathrm{b}}$ & & \\
\hline Betel Leaf $(50 \%)$ & $26.00^{\mathrm{b}}$ & & \\
\hline Slaked Lime (100\%) & $16.67^{\mathrm{c}}$ & & \\
\hline Slaked Lime (50\%) & $23.67^{\mathrm{b}}$ & & \\
\hline
\end{tabular}

Legend:

** - highly significant

Means of the same letter are not significantly different at $1 \%$ level of significance 
Moreover, the $100 \%$ and $50 \%$ concentration of betel quid were not significantly different from the $100 \%$ concentration of areca nut while the 50\% betel quid, $100 \%$ and $50 \%$ areca nut and $100 \%$ slaked lime were not significantly different from each other. The $100 \%$ and $50 \%$ betel leaf are not significantly different from the $50 \%$ slaked lime.

Cytotoxic Effects of the Betel Quid and Components in Terms of Mitotic Index

Cells in various phases of mitosis after 48 hours of exposure to the different extracts were evaluated by photomicroscopy and the results are shown in table 3 as percentages of cells in mitosis. Mitotic index is used as an indicator of cell proliferation biomarkers which measure the proportion of cells in the mitotic phase of the cell cycle.

Table 2 presents the effects of the various treatments on Allium cepain terms of mitotic index. The 100\% betel quid had the most drastic effect with the mitotic index of $7 \%$ followed by the $100 \%$ areca nut while the $50 \%$ betel leaf and slaked lime had the least effect with the mitotic index of $12.13 \%$. The $100 \%$ and $50 \%$ areca nut had a mitotic index of $8.40 \%$ and $15.60 \%$ respectively. The Allium treated with $100 \%$ betel leaf had a lower mitotic index of $13.33 \%$ while the $50 \%$ betel leaf had a higher mitotic index of $19.80 \%$. Moreover, the Allium treated with $100 \%$ and $50 \%$ slaked lime had the mitotic index of $12.13 \%$ and $17.53 \%$ respectively.

Statistical analysis of the different treatments showed that the betel quid and its components significantly affected the percentage of mitotic index of the Allium cepa roots.

Table 2. Effects of the betel quid and components in terms of mitotic index (\%)

\begin{tabular}{|c|c|c|c|}
\hline COMPONENTS & MEAN & "F-VALUE & SIG. \\
\hline Negative Control (Distilled water)) & $26.53^{\mathrm{a}}$ & $14.753 * *$ & 0.000 \\
\hline Positive Control (Colchicine) & $6.47^{\mathrm{g}}$ & & \\
\hline Betel Quid (100\%) & $7.00^{\mathrm{fg}}$ & & \\
\hline Betel Quid (50\%) & $12.13^{\mathrm{def}}$ & & \\
\hline Areca Nut $(100 \%)$ & $8.40^{\text {efg }}$ & & \\
\hline Areca Nut $(50 \%)$ & $15.60^{\mathrm{bcd}}$ & & \\
\hline Betel Leaf (100\%) & $13.33^{\text {cde }}$ & & \\
\hline Betel Leaf (50\%) & $19.80^{\mathrm{b}}$ & & \\
\hline Slaked Lime (100\%) & $12.13^{\mathrm{def}}$ & & \\
\hline Slaked Lime (50\%) & $17.53^{\mathrm{bc}}$ & & \\
\hline
\end{tabular}

Means of the same letter are not significantly different at $1 \%$ level of significance

This may indicate that betel quid and areca nut extract exerted a cytotoxic effect at $100 \%$ compared to the $100 \%$ betel leaf and slaked lime. The mitotic indices in treated cells were lower compared to the distilled water (negative control). As shown in the table 2, the mitotic index decreased as the concentration increased from 50\% to $100 \%$.

Cytotoxic Effects of the Betel quid and its Components in Terms of Chromosomal Aberrations

Microscopic examination in Allium test allows assessment of chromosome damage and cell division disturbances, thus providing additional information as to the severity or mechanism of the toxic effects. Chromosome aberrations (chromosome bridges, chromosome fragment, sticky chromosome, laggard chromosome and vagrant chromosome) were observed during metaphase to telophase stage of the mitotic phase of cell cycle. Representative pictures of different types of chromosomal abnormalities are presented in Plate 7.

Figure 1 presents the effects of the betel quid and its components as to chromosomal aberrations. Statistical analysis revealed that the $100 \%$ and $50 \%$ of betel quid and areca nut had the most extreme effect on the Allium cepa 
root. Specifically, it was shown that $50 \%$ and $100 \%$ of the betel quid and areca nut had the highest chromosomal aberrations with a mean value ranging from 24 to 35.33 which is comparable to the positive control. On the other hand, $100 \%$ and $50 \%$ of betel leaf and slaked lime had the lowest chromosomal aberrations with 4.33 to 8.67 . The $100 \%$ and $50 \%$ of betel quid and areca nut are not significantly different from each other. The effect of $100 \%$ and $50 \%$ betel leaf and slaked lime are not significantly different from negative control. It was observed though that the negative control had no chromosomal aberrations as compared to the other components.

Figure 3. Chromosomal aberrations of the betel quid and various components

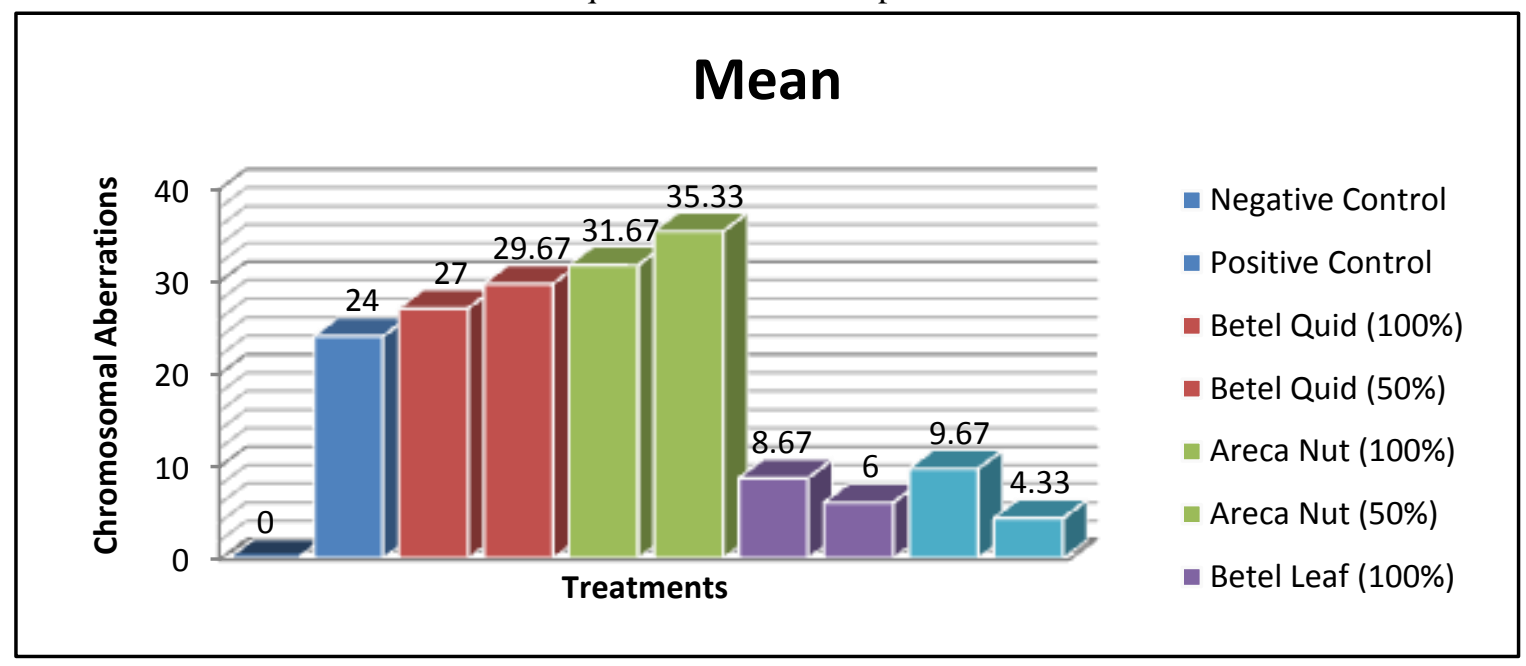

\section{Discussion}

Theroot length can be observed higher as concentration is reduced as shown in theresults that all tested concentrations of the extracts of the betel quid and its component caused significant inhibition in the growth of roots in comparison to the negative and positive control. The inhibition of the root length was greater with the increasing concentrations of the betel quid and its components.

The changes/decrease in mitotic index of Allium cepa cells are indicators of the cytotoxic potential of the betel quid and its components and the blockage of the cell cycle phases specifically in the Gap 2 phase resulting to the prevention of the cell to undergo mitosis or the occurrence DNA synthesis might be inhibited that caused the decrease in the mitotic activity. The results herein suggest that the betel quid and its components extracts have the inhibitory, mito-depressive effects on the root growth and cell division of Allium cepa.

According to the study of Del Socorro et al. (2014) the cytotoxic activity of Betel leaf was assessed using brine shrimp and it was found to be containing cytotoxic compounds indicating the presence of cytotoxic components of the plant.

Results of the present study corroborate with the study by Chetan et al. (2010) proving cytotoxicity activity of various parts of medicinal plants such as Agave americana, Strychnosnuxvomicaand Areca catechu fruits. Their study revealed that methanol extract of Agave americanaand aqueous extract of Areca catechu have potent cytotoxicity to the human cells.

There are also studies such as Ma et. Al (2013) that Piper betel leaf has its ability to prevent foam cell formation in a model for oxidised low density lipoprotein (oxLDL)-induced lipid accumulation in macrophages.It may also be possible that the Betel quid and components causes genetic damage that resulted in the release of chemical signals that enhanced the rate of cell cycle without causing cytotoxicity. A study by Sundqvist et al. (1991) stated that the Betel nut and the betel leaf have demonstrated mutagenic, carcinogenic, and genotoxic properties in vitro and in animal experiments. 
It has been noted from the study of Boucher et al. (2002) that rats that were regularly fed with betel nut showed increase in serum aminotransferase and also the increase in the prevalence of hepatocellular carcinoma among the betel quid chewers and it is proved from the result of Tsai et al. (2004) that this effect may be due to the safrole content present in the betel leaf that is in high amount which has been connected in the formation of cancer in the liver and was observed in the saliva of betel quid chewers. Roy et al. (2013) investigated the cytotoxic activity of betel leaf and that it was indicative that betel leaf extract exhibited a dose dependent cell killing. Betel leaf displayed cytotoxicity towards both normal and tumor cell lines, the toxicity on tumor cells was far greater than that on normal cells indicating selective toxic effect of the plant extract on the tumor cells.

In this study, cytotoxic effects of the extracts of the betel quid and its components were assessed by analyzing the root length and the cytological parameters such as the mitotic index and chromosome aberrations. Between the inhibition of the length of root and mitotic index, a positive correlation was found. The decline of MI below $22 \%$ in comparison to negative control can have lethal impact on the organism (Antonsie-wiez, 1990), while a decrease below 50\% usually has sublethal effects (Panda et al., 1985) and is called cytotoxic limit value (Sharma, 2002)

It also shows that the trend of chromosome aberrations generally increases as the concentration of the betel quid and its component extracts becomes higher. Chromosome aberrations are indicated by the change in the structure of chromosome or chromosomes total number. In this study chromosome aberrations were observed such as the chromosome bridge that mainly rises due to exposure of a mutagen (Soumyashree et al., 2014). According to Fiskesjo (1985), sticky chromosomes indicated a highly toxic, irreversible effect, probably leading to cell death. The presence of chromosome fragments is an indication of chromosome breaks, and can be a consequence of anaphase/telophase bridges (Sharma, 2002). Results of the study reflected the utility of the root tip cells of Allium cepa for monitoring the cytotoxic effects of the extracts of the betel quid and its components.

\section{Conclusions}

Based from the results of the study, these are the following conclusions:

1. The betel quid and its components have the potential to inhibit the growth of the Allium cepa as shown in the significant decrease in the length of root and capable of inhibiting the rate of cell division in the Allium cepa root tip as shown in the significant decrease in the mitotic index. Among the different treatments, the betel quid has the greatest potential to inhibit the growth of the Allium cepa as shown in the significant decrease in the length of root. and the most capable of inhibiting the rate of cell division in the Allium cepa root tip as shown in the significant decrease in the mitotic index and increase in the formation of chromosome aberration. This implies that the betel quid and its components have cytotoxic potentials. There are constituents of the betel quid and its components that are capable of inducing direct chromosome / DNA damage or indirect mechanisms that lead to the damage of the genetic material in Allium cepa.

\section{References}

[1] Antonsie-wiez, D. (1990).Analysis of the cell cycle in the root meristem of Allium cepa under the influence of Leda krin. Folia Histochemica et Cytobiologica;26:79-96. [PubMed]

[2] Boucher, B.J \& Mannan, D. (2002). Metabolic effects of the consumption of Areca catechu. Addict Biol.103-10. Retrieved from: https://www.ncbi.nlm.nih.gov/pubmed/11900629

[3] Chetan, A.C, Rajesh, P., Sanjay, D., Jitesh , J. (2010). In vitro cytotoxicity study of agave americana, strychnosnuxvomica and areca catechu extracts using mcf-7 cell line

[4] Del Socorro, M.L., Bendoy, C.P., \&Dacayana, C.L. (2014). Cytotoxic effects of Betel vine, Piper betle

[5] Linn. Leaf Extracts Using Artemia salina Leach (Brine shrimp assay). Retrieved from: http://dx.doi.org/10.7828/jmds.v3il.629

[6] Fiskesjo, G. (1985). The Allium Test as a Standard in Environmental Monitoring. Sweden. Institute of Genetics.

(C) 2019, IJSMS 
[8] Guerra, M, \& Souza, M.J. (2002). How to observe chromosomes: A guide of technique in plant cytogenetics, animals and human . São Paulo ,Funpec IARC (2004)Monographs on the Evaluation of Carcinogenic Risks to nut chewing and Some Areca-nut-derived Nitrosamines, Lyon, IARC Press

[9] Ma, G.C, Wu, P.F., Tseng, H.C., Chyau, C.C., Lu, H.C., Chou, F.P. (2013). Inhibitory effect of Piper betel leaf extracts on copper-mediated LDL oxidation and oxLDL-induced lipid accumulation via inducing reverse cholesterol transport in macrophages.

[10] Nair, U.J., Friesen,M., Richard, I., Maclennan, R., Thomas, S. \& Bartsch, H. (1990). Effect of lime composition on the formation of reactive oxygen species from areca nut extract in vitro.

[11] Panda, B.B., \&Sahu, U.K. (1985). Induction of abnormal spindle function and cytokinesis inhibition in mitotic cells of Allium cepa by the organophosphorus insecticide fensulfothion. Cytobios.;42(167-168):147-155.

[12] Pradhan,D., Suri, K. A. \&Biswasroy, P. (2013). Journal of Pharmacognosy and Phytochemistry. Volume 1 No. 62013. www.phytojournal.com

[13] Philippine Daily Inquirer. (2007).Cordillerans warned betel nut chewing can cause cancer pp. 15

[14] Roy, U. \&Vijayalaxmi, K. (2013). Evaluation of cytotoxic activity of Piper betle Linn. using murine and human cell lines in vitro. International Journal of Scientific \&Engineering $\quad$ Research, 4 (9), 221-233.

[15] Sharan, R.N., Mehrotra, R., Choudhury, Y., Asotra, K. (2012). Association of Betel nut with carcinogenesis: Revisit with clinical perspective.

[16] Sharma, A. \&Sen, S. (2002) Chromosome Botany. Enfield, NH, USA: Science.

[17] Soumyashree, N., Kumar hemanth, N.K. \& Jagannath, S. (2014). Evaluation of cytotoxic efficacy of dairy effluent on root meristem cells of garlic (Allium sativum L.), International Journal of Science, Environment and Technology, Vol. 3, No 4, 2014, 1440 - 1449

[18] Sundqvist K., Liu, Y. \& Nair, J. (1989-1995). Cytotoxic and genotoxic effects of areca nut-related compounds in cultured human buccal epithelial cells. Cancer Res, 49:5294-5298. PMID: 2766297

[19] Tsai, J.F., Jeng, J.E, Chuang, L.Y. (2004) Habitual betel quid chewing and risk for hepatocellular carcinoma complicating cirrhosis. Medicine (Baltimore) .;83(3):176-187. 